\title{
Potencjał słowotwórczy wybranych czasowników dźwiękonaśladowczych w języku czeskim i polskim
}

Onomatopeje (czes. zvukomalebná slova) stanowią ,zupełny margines w słowotwórstwie polszczyzny" - pisze Mirosław Skarżyński we wstępie do czwartego tomu Stownika gniazd słowotwórczych wspótczesnego języka ogólnopolskiego. Gniazda motywowane przez liczebniki, przystówki, zaimki, przyimki, modulanty, onomatopeje, wykrzykniki ${ }^{1}$, w którym przedstawia 13 gniazd motywowanych przez onomatopeje ${ }^{2}$ - składają się na nie 63 derywaty. W tomie opisującym gniazda odczasownikowe (SGS, t. 3) można jednak znaleźć wiele czasowników bazowych spokrewnionych z różnego rodzaju onomatopejami. Mirosław Bańko, autor Wspótczesnego polskiego onomatopeikonu i Stownika onomatopei, definiuje onomatopeję — czy też interiekcję onomatopeiczną — następująco:

Onomatopeja to: 1. tworzenie lub użycie wyrazów z intencją naśladowania dźwięków bądź ruchów, którym takie dźwięki mogą towarzyszyć (a także z intencją naśladowania pewnych cech dźwięków mowy, lecz nie ich wiernego powtarzania); 2. wyraz lub wyrażenie będące wynikiem takiego działania ${ }^{3}$.

M. Bańko w hasłach swojego onomatopeikonu podaje wykrzykniki dźwięko- i ruchonaśladowcze oraz rodzinę wyrazów w jakiś sposób z nią związaną. Wśród tych onomatopei można wyróżnić: nazwy głosów zwierząt (typu: BEE, BZZ, CHRUM, CIR, ĆWIR, KLE), związane z czasownikami: beknąć, beczeć, bzyczeć, chrumkać, cirykać, czyrykać, ćwierkać, klekotać; nazwy dźwięków po-

${ }^{1}$ Stownik gniazd słowotwórczych wspótczesnego języka ogólnopolskiego, t. 3-4, red. M. Skarżyński, Kraków 2004, s. X, dalej: SGS.

${ }^{2}$ Kryterium przyjęte przez autora 4 tomu SGS o uwzględnieniu onomatopei jako podstaw gniazd słowotwórczych było zgodne z założeniami przyjętymi dla całego SGS.

${ }^{3}$ M. Bańko, Wspótczesny polski onomatopeikon, Warszawa 2008, s. 18. 
wstających przy różnego rodzaju uderzeniach (typu: PAC, PIK, PLASK, PLUSK, PUK, RYMS, RYP, STUK, STUK), związane z czasownikami: pacać, pikać, plaskać, pluskać, pukać, rymsnać, rypsnać, stukać; nazwy dźwięków towarzyszących różnego rodzaju czynnościom (CHU, CIACH, CYK, CZLAP, DMUCH, GUL, GUL), połączone z czasownikami: chuchać, ciachać, cykać, człapać, dmuchać, gulgotać.

Językoznawca nie analizuje szczegółowo stopnia pokrewieństwa wyrazów związanych z onomatopeją. W niektórych przypadkach onomatopeja zdaje się być podstawą dla wyrazów spokrewnionych: BEE $\rightarrow$ beczeć, PLUSK $\rightarrow$ pluskać, ale zdarza się, że to ona jest derywatem: gadu-gadu $\leftarrow$ GADAĆ.

Tadeusz Szymański w swojej monografii Derywacja czasowników onomatopeicznych i ekspresywnych w języku bułgarskim pisze:

Przy tworzeniu wyrazów onomatopeicznych kolejność derywacyjna jest następująca: prymarna interiekcja $\rightarrow$ czasownik $\rightarrow$ derywat odczasownikowy, którym może być sekundarna interiekcja, rzeczownik lub czasownik ekspresywny ${ }^{4}$.

Definicja ta nie pozwalałaby traktować czasowników dźwiękonaśladowczych jako prymarnych, a tym samym jako podstaw gniazda słowotwórczego, gdyby nie fakt, że ostatecznie nie można stwierdzić, czy interiekcja jest podstawą dla danego czasownika, na przykład BZZ ... dla bzyczé́; można ją natomiast potraktować jako „współczesny polski kontynuant dawnych interiekcji dźwiękonaśladowczych, które dały początek wymienionym czasownikom"s. $\mathrm{Z}$ tego powodu w analizie gniazd słowotwórczych czasownik dźwiękonaśladowczy traktuję jako niemotywowaną podstawę gniazda — ani synchronicznie, ani diachronicznie nie ma możliwości określenia jego faktycznej podstawy słowotwórczej.

Analizie poddano 6 gniazd czasowników dźwiękonaśladowczych, związanych przede wszystkim z odgłosami towarzyszącymi jedzeniu i piciu, które mogą występować także przy innych czynnościach. Czasowniki wyjściowe znajdują się w definicjach słownikowych onomatopeikonu Bańki (2008), a ich gniazda są opisane w Stowniku gniazd słowotwórczych (SGS, t. 3). Dla języka czeskiego dobrano odpowiednie ekwiwalenty semantyczne będące pochodnymi onomatopei ${ }^{6}$. W SGS (t. 3) pary aspektowe różniące się tematem fleksyjnym — czasownik dokonany i niedokonany o tym samym znaczeniu leksykalnym - są traktowane jako nieutworzone (podstawy gniazda) lub jako utworzone na jednym takcie derywacyjnym (SGS, t. 3, s. IX). Analogicznie potraktowałam czasowniki języka czeskiego.

${ }^{4}$ T. Szymański, Derywacja czasowników onomatopeicznych i ekspresywnych w języku bułgarskim, Wrocław 1977, s. 17.

${ }^{5}$ M. Bańko, op. cit., s. 79.

${ }^{6}$ Główne źródło stanowiło internetowe wydanie Slovnika spisovného jazyka českého z lat 1960-1971 (dalej: SSJČ), w którym wyszukiwanie następuje według haseł lub według zawartości definicji słownikowej, możliwe jest także wyszukiwanie fragmentów wyrazów, co ułatwia ustalenie rodziny wyrazów spokrewnionych. Dodatkowo uzupełniłam niektóre gniazda o leksemy występujące w Narodowym Korpusie Języka Czeskiego (dalej: SYN 2015). 
Analizie poddane zostały gniazda czasowników:

1) HLTAT / ŁYKAĆ, ŁYKNĄĆ;

2) CHLEMTAT, CHLEMTNOUT, CHLEMSTAT, CHLEMSTNOUT, CHLAMSTAT, CHLAMSTNOUT / CHŁEPTAĆ;

3) CHROUPAT, CHROUPNOUT, CHŘOUPAT, CHŘOUPNOUT, CHŘUPAT, CHŘUPNOUT / CHRUPAĆ, CHRUPNĄĆ;

4) MLASKAT, MLASKNOUT / MLASKAĆ, MLASNĄĆ;

5) SRKAT, SRKNOUT / CHLIPAĆ, CHLIPNĄĆ;

6) ŠPLOUCHAT, ŠPLOUCHNOUT, ŠPLÍCHAT, ŠPLÍCHNOUT, ŠPLÁCHAT, ŠPLÁCHNOUT / CHLUPAĆ, CHLUPNĄĆ.

Gniazdo słowotwórcze składa się z konkretnych derywatów, lecz — gdy zwróci się uwagę tylko na znaczenia tych derywatów i zestawi ze sobą gniazda danej klasy leksykalno-semantycznej — dzięki analizie gniazdowej można obserwować procesy słowotwórcze od strony ich powtarzalności. Służą temu dwie mniejsze jednostki gniazda: typowy paradygmat słowotwórczy i łańcuch słowotwórczy ${ }^{7}$.

\section{Typowy paradygmat słowotwórczy (TPS)}

Najbardziej rozbudowany jest typowy paradygmat słowotwórczy I taktu, czyli zbiór znaczeń wyrażanych przez derywaty bezpośrednio utworzone od wyrazu bazowego gniazda ${ }^{8}$. W obu językach wystąpił blok rzeczownikowy, czasownikowy i przymiotnikowy, przy czym w niniejszej pracy koncentruję się tylko na dwóch pierwszych częściach mowy. Aby dana kategoria semantyczna weszła w skład typowego paradygmatu słowotwórczego, przyjęłam zasadę, że musi ona wystąpić w paradygmatach co najmniej trzech gniazd. W analizie kategorii słowotwórczych posługuję się przede wszystkim terminologią Gramatyki współczesnego języka polskiego ${ }^{9}$. Użycia kontekstowe pochodzą przeważnie z tekstów zgromadzonych

${ }^{7}$ Zob. M. Dokulil, Tvořeni slov v češtině, t. 1. Teorie odvozováni slov, Praha 1962, s. 18; I. Burkacka, Porównawcza analiza gniazdowa wybranych leksemów neutralnych $i$ nacechowanych ekspresywnie, Warszawa 2001, s. 14; A. Nagórko, Zarys gramatyki polskiej, Warszawa 2003, s. 227; L. Jochym-Kuszlikowa, Metoda analizy gniazdowej w konfrontatywnych badaniach stowotwórstwa wspótczesnego języka polskiego i rosyjskiego, Kraków 1982, s. 20-21.

8 Zob. Е.А. Земская, О парадигматических отнотениях в словообразовании, [w:] Русский язык. Вопросы его истории и современного состояния, red. Н.Ю. Шведовей, Москва 1978, s. 71; L. Jochym-Kuszlikowa, Jednostki systemowe stowotwórstwa a polsko-rosyjskie badania konfrontatywne, „Slavia Orientalis” 29, 1980, z. 1-2, s. 106; H. Jadacka, Rzeczownik polski jako baza derywacyjna. Opis gniazdowy, Warszawa 1995, s. 23.

9 Gramatyka wspótczesnego języka polskiego, t. 2, red. R. Grzegorczykowa, R. Laskowski, H. Wróbel, Warszawa 1999. 
w narodowych korpusach językowych obu języków (SYN 2015, NKJP ${ }^{10}$ ), przy czym kontekst nie zawsze odnosi się do jedzenia i picia.

\subsection{Blok rzeczownikowy}

Blok rzeczownikowy reprezentuje jedna kategoria słowotwórcza spełniająca warunek minimalnej liczby wystąpień - są to nazwy wytworów czynności. Derywaty nazywają zjawiska akustyczne, odgłosy towarzyszące jedzeniu i piciu: chlamst, chlemst, mlask, srkot, šplichot, lecz także mlaskavka jako 'mlaskana głoska':

Chlamst, chlamst, žral jsem kola tlačenky, chleby, žaludek se mi rozlil až do stehen. (SYN 2015)

Pak se vynoří okrouhlá ústa, udělá to mlask! — a mám jasno. Dívám se na trofejního kapra. (SYN 2015)

A mezi těmi sny obrysy pevniny, vrch a důl. Slyší sykot, svištění, srkot. (SYN 2015)

[...] totiž na dotaz, co si myslí o naší roli a úkolu, [...] odpověděl řadou mlaskavek, jež zřejmě poukazovaly na řeč domorodců. (SYN 2015)

Tę kategorię słowotwórczą realizują derywaty: chlupot, chrupot, mlask, mlaskot, oraz mlask 'spółgłoska', należące do trzech gniazd czasowników dźwiękonaśladowczych języka polskiego:

To jest na jeden mlask, sama rozkosz. Czujesz czosnek? (NKJP)

Po chwili słychać stamtąd odgłosy wody płynącej z kurków, chlupot i parskanie. (NKJP)

Brzękanie łańcuchów przy żłobach, równy chrupot buraków w pyskach koni, parskanie, szelest deptanej ściółki [...]. (NKJP)

W językach khoisan występują mlaski boczne. (NKJP)

\subsection{Blok czasownikowy}

Dość reprezentatywną grupą w języku czeskim są formacje charakterystyki bezwzględnej, mówiące o intensywności i efektywności akcji podstawy. Mogą oznaczać wzmocnienie akcji, odnosić się do poczucia nasycenia: nachlamstat se, nachlemstat se, nachlemtat se, nachroupat se, nahltat se (także w znaczeniu przenośnym), choć wystąpił też czasownik o znaczeniu ewolutywnym: rozchlemtat se. Czasowniki te wchodzą w skład trzech gniazd, przy czym dotyczą zarówno jedzenia, jak i picia — również w znaczeniu przenośnym:

Krávy se nachlemstaly z potoka. (SSJČ)

[...] pojd'me se naprásknout a nachlemtat, až nám tuk poteče po bradě. (SSJČ)

A potom jsou závodníci, pokračoval, kteří se tolik nahltali [...] smrti, že už jim přestala chutnat. (SYN 2015)

W języku polskim tego typu derywaty — nachteptać się, nałykać się - wystąpiły w dwóch gniazdach, a ich użycia kontekstowe są dosłowne i przenośne:

${ }^{10}$ P. Pędzik, Narodowy korpus języka polskiego. Wyszukiwarka PELCRA dla danych NKJP, red. A. Przepiórkowski et al., Warszawa 2012, http:www.nkjp.uni.lodz.pl, dalej: NKJP. 
Hamid leży na granicy cienia [...], pogrążony we śnie niczym kot, który nachłeptał się śmietany [...]. (NKJP)

Cała trójka nałykała się dymu, a kobieta dodatkowo zasłabła przestraszona pożarem. (NKJP) Z Akademii Monachijskiej wyniosła znakomity warsztat, w Paryżu nałykała się świadomości twórczej, wszystko to dawało znakomite rezultaty [...]. (NKJP)

Drugą grupę derywatów tej kategorii słowotwórczej stanowią formacje wyrażające osłabienie intensywności i efektywności akcji podstawowej: pochrupovat, pochroupávat, pomlaskat, pomlasknout, pomlaskovat, pomlaskávat, posrkovat, posrkávat, nasrknout:

Koně pochrupovali seno. (SSJČ)

Když se vzrušil nebo byl nadržený, tak vždycky vyšpulil rty a pomlaskával. (SYN 2015)

A zatímco pomalu posrkávali, hlas Louise Satchma Armstronga z magnetofonu tvrdil: ,jaký nádherný svět ... vidím [...]”. (SYN 2015)

W języku polskim czasowniki o tym znaczeniu wystąpiły tylko w dwóch gniazdach: CHŁEPTAĆ $\rightarrow$ pochteptać, MLASKAĆ $\rightarrow$ pomlaskać:

I dotknąwszy ledwo brzegu kielicha ustami, pomlaskal i odstawił. (NKJP)

Mleka jeszcze czasem pochleptal, ale chleba, sera, boczku czy nawet mięsa z kurzej łydy nie tknął [...]. (NKJP)

Od czasowników dźwiękonaśladowczych w języku czeskim tworzy się także formacje fazowe, oznaczające rozpoczęcie czynności: zamlaskat, zasrkat, zašplouchat, zachroupat, zachrupat. Tutaj również zaklasyfikowałam czasowniki dokonane, podobne do formacji semelfaktywnych, znamionujące rozpoczęcie krótkiej czynności: zamlasknout, zasrknout:

Smutně zamlaskala, když uslyšela o smrti dvaatřicetiletého mladíka. (SYN 2015)

Na stole zacinkaly př́ibory a červené víno, které Sam pil, zašplouchalo ve sklenici. (SYN 2015)

Stiskl jí prsty, až v nich zachřupalo. (SSJČ)

W języku polskim na I takcie wystąpiły dwie formacje tego typu: zachlupać, zamlaskać, w związku z czym nie tworzą one klatki paradygmatu typowego. Podobne formacje wystąpiły na III takcie derywacji: chrupotać $\rightarrow$ zachrupotać, chlupotać $\rightarrow$ zachlupotać.

W gniazdach czasowników dźwiękonaśladowczych na I takcie wystąpiły także formacje kompletywne, oznaczające objęcie akcją wszystkich przedmiotów: vysrkat, vychlemtat, vychlemstat, vychlemstávat, vychlemstnout, vymlasknout ${ }^{11}$ :

Vděčně vysrkal sklenici vody, kterou mu podala máma [...]. (SYN 2015)

Ožralé prase den leželo jako mrtvé, pak se probralo a vychlemtalo kastrol vody. (SYN 2015)

Ráno vymlaskl nejdražší psí konzervu, kterou jsme v okolí sehnali [...]. (SYN 2015)

W języku polskim formacje kompletywne wychlipać, wychłeptać, wychłeptywać należą do dwóch gniazd, nie wchodzą więc w skład TPS języka polskiego.

Wśród analizowanych czasowników znajdują się także derywaty, które trudno jest jednoznacznie zaklasyfikować, na przykład: vhltat; vmlasknout; prechroupnout,

11 Derywat pochodzi z SYN 2015. 
rozchroupat, uchroupnout; odsrkat, usrknout, vsrkat; rozšplichat. W gramatyce akademickiej języka czeskiego ${ }^{12}$ są one traktowane jako derywaty wskazujące na kierunek działania, a dokładnie - na oddalenie od siebie części (rozšplíchat), odebranie czegoś (odsrkat, uchroupnout, usrknout), umieszczenie przedmiotu wewnątrz czegoś (vhltat, vsrkat, vmlasknout — zjeść coś, wypić poprzez łykanie, chlipanie, mlaskanie), naruszenie całości, rozdzielenie na części (přechroupnout, rozchroupat). W monografii Šmilauera ${ }^{13}$ można przeczytać między innymi o słowotwórczej funkcji przedrostka $u$ - w formacjach kierunkowych, lecz także w formacjach oznaczających małą ilość, fragmentaryczność: ubrat medu, ulit vína - z wciąż obecnym znaczeniem oddzielenia części od całości, czyli określeniem kierunku działania. Wydaje się, że metodologia przyjęta przez autorów Gramatyki wspótczesnego języka polskiego nakazywałaby włączyć takie derywaty do formacji charakterystyki bezwzględnej — osłabienia intensywności akcji podstawy: usrknout 'srkavě upít', podczas gdy upit oznacza 'pitím ubrat (tekutiny), trochu se napít'.

Chociaż nie ma tego typu formacji w analizowanych gniazdach czasowników dźwiękonaśladowczych języka polskiego — z wyjątkiem odchlipać 'chlipiąc, upić trochę' - samo znaczenie jest wyrażane przez inne czasowniki oznaczające jedzenie i picie: upić, odgryźć, przegryźć, przekąsić, nadgryźć - temu ostatniemu w Gramatyce... przypisano znaczenie osłabienia efektywności akcji podstawy ${ }^{14}$. Ostatecznie traktuję te formacje jako kierunkowe „oddzielenie części od całości” $\mathrm{z}$ dodatkową informacją o osłabieniu akcji.

Ostatnią grupę stanowią derywaty, w których zmianie ulega wyłącznie aspekt podstawy w wyniku prefiksacji: po-hltit, po-hlcovat, pre-hltnout, se-srknout, s-chlamstat, s-chlamstnout, s-chlemstnout, s-chroupat, s-chroupnout, s-chrupat, s-chrupnout, u-srkovat, u-srkávat, z-hltnout, z-hltat, z-hltit, z-hltávat.

Tego typu formacje wystąpiły tylko $\mathrm{w}$ jednym $\mathrm{z}$ analizowanych gniazd języka polskiego: ŁYKAĆ, ŁYKNĄĆ $\rightarrow$ po-tknać, prze-tykać, prze-łknać. Pojawia się zatem pytanie, czy ujmować te derywaty w paradygmacie słowotwórczym, skoro aspekt jest kategorią fleksyjną? Na tym etapie analizy sygnalizuję jedynie ich obecność.

\section{2. Łańcuchy słowotwórcze}

Łańcuch słowotwórczy to ciąg wyrazów zaczynający się wyrazem bazowym gniazda, którego bezpośredni derywat na I takcie stanowi podstawę derywacji dla derywatu II taktu, który z kolei jest podstawą derywatu III taktu

12 M. Dokulil, J. Krouz, Mluvnice češtiny, t. 1. Fonetika. Fonologie. Morfonologie a morfemika. Tvoření slov, Praha 1986.

13 V. Šmilauer, Novočeské tvoření slov, Praha 1971, s. 175, 181-182.

14 Gramatyka wspótczesnego języka..., s. 551. 
i tak dalej ${ }^{15}$. Analiza tego typu ciągów pokazuje potencjał gradualnego procesu tworzenia słów ${ }^{16}$.

Łańcuchy słowotwórcze analizowanej grupy są w przeważającej ilości dwuelementowe - składają się na nie czasownik podstawowy i czasownik derywowany (I takt). Relacje te zostały pokazane w ramach opisu paradygmatu typowego. Znacznie mniejszą grupę stanowią łańcuchy trójelementowe, w których można odnaleźć regularne proporcje słowotwórcze ${ }^{17}$ — przy czym inne dla każdego z języków.

W języku czeskim wśród 20 łańcuchów o trzech, czterech i pięciu ogniwach za powtarzalny model można uznać ten składający się z: bazowego czasownika $\rightarrow$ przymiotnika (II takt) $\rightarrow$ przysłówka (III takt):

1) CHLEMSTAT $\rightarrow$ chlemstavý $\rightarrow$ chlemstavé;

2) CHRUPAT $\rightarrow$ chrupavý $\rightarrow$ chrupavé;

3) HLTAT $\rightarrow$ hltavý $\rightarrow$ hltavé; HLTAT $\rightarrow$ hltný $\rightarrow$ hltné;

4) SRKAT $\rightarrow$ srkavý $\rightarrow$ srkavé;

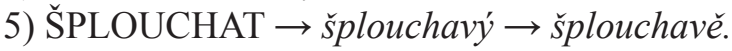

Najdłuższe łańcuchy w języku czeskim nie powielają jednak modelu trójelementowego: HLTAT $\rightarrow$ hltavý $\rightarrow$ hltoun $\rightarrow$ hltounský $\rightarrow$ hltounství lub hltounsky.

W języku polskim wśród 13 łańcuchów mających więcej niż dwa ogniwa można wyodrębnić jeden powtarzalny model: bazowy czasownik $\rightarrow$ rzeczownik I taktu (nazwa wytworu czynności) $\rightarrow$ czasownik II taktu (formacje od nazw zdarzeń):

1) CHLUPAĆ $\rightarrow$ chlupot $\rightarrow$ chlupotać;

2) CHRUPAĆ $\rightarrow$ chrupot $\rightarrow$ chrupotać;

3) MLASKAĆ $\rightarrow$ mlask $\rightarrow$ mlaszczeć.

W gnieździe czasownika chlupać znajdują się najdłuższe łańcuchy, przy czym jeden jest rozszerzeniem modelu o trzech ogniwach:

1) CHLUPAĆ $\rightarrow$ chlupot $\rightarrow$ chlupotliwy $\rightarrow$ chlupotliwie;

2) CHLUPAĆ $\rightarrow$ chlupot $\rightarrow$ chlupotać $\rightarrow$ zachlupotać lub z ostatnim ogniwem: rozchlupotany.

\section{Podsumowanie}

Analizie poddano 6 gniazd języka czeskiego i polskiego. W języku czeskim składa się na nie 85 derywatów (20 rzeczowników, 43 czasowniki, 15 przymiotników, 8 przysłówków), a w języku polskim — 49 derywatów (18 rzeczowników, 21 czasowników, 9 przymiotników, 1 przysłówek).

15 Zob. M. Dokulil, op. cit., s. 11; I. Burkacka, op. cit., s. 14; A. Nagórko, op. cit., s. 227; L. Jochym-Kuszlikowa, Metoda analizy gniazdowej..., s. 20-21.

16 E.A. Karpiłowska, Gniazda stów jako językowy obraz świata. Perspektywy badań porównawczych, „LingVaria” 2, 2007, nr 2 (4), s. 33.

17 Zob. M. Dokulil, op. cit., s. 14. 
Już na początku badania widać różnicę między wariantywnością form fleksyjnych czasowników w języku polskim i czeskim. W czeskim podstawę gniazda stanowią: czasownik niedokonany, para lub kilka par aspektowych. W języku polskim jest to bądź czasownik niedokonany, bądź para aspektowa. Podobna sytuacja może mieć miejsce również na kolejnych taktach derywacji. W języku czeskim TPS składa się z jednej kategorii słowotwórczej rzeczowników i czterech czasownikowych, grupy czasowników dokonanych oraz z przymiotników. W języku polskim są to dwie kategorie słowotwórcze: rzeczownikowa, czasownikowa oraz przymiotniki odczasownikowe.

W tabeli podano wszystkie derywaty słowotwórcze realizujące konkretne znaczenia - z pominięciem wariantów fleksyjnych. Klatki paradygmatu z derywatami w nawiasach należy traktować jako puste, ponieważ realizowane znaczenia nie spełniają warunku minimalnej liczby wystąpień.

\begin{tabular}{|c|c|c|c|c|}
\hline \multicolumn{5}{|c|}{ Typowy paradygmat słowotwórczy I taktu } \\
\hline Klasa derywatów & Język czeski & W gniazdach & Język polski & W gniazdach \\
\hline $\begin{array}{l}\text { nazwy wytworów } \\
\text { czynności i procesów } \\
\text { (zjawiska akustyczne) }\end{array}$ & $\begin{array}{l}\text { chlamst, hlt, mlask, } \\
\text { srkot, šplíchot }\end{array}$ & $5 / 6$ & $\begin{array}{l}\text { chlupot, } \\
\text { chrupot, mlask, } \\
\text { mlaskot }\end{array}$ & $4 / 6$ \\
\hline $\begin{array}{l}\text { formacje charakte- } \\
\text { rystyki bezwzględnej } \\
\text { (wzmocnienie/osła- } \\
\text { bienie akcji wyrażo- } \\
\text { nej podstawą) }\end{array}$ & $\begin{array}{l}\text { nachlamstat se, roz- } \\
\text { chlemtat se, nachroupat } \\
\text { se, nahltat se; pochru- } \\
\text { povat, pomlaskovat, } \\
\text { posrkovat, nasrknout }\end{array}$ & $6 / 6$ & $\begin{array}{l}\text { nałykać się, } \\
\text { nachłeptać się; } \\
\text { pochłeptać, } \\
\text { pomlaskać }\end{array}$ & $3 / 6$ \\
\hline $\begin{array}{l}\text { formacje komple- } \\
\text { tywne }\end{array}$ & $\begin{array}{l}\text { vysrkat, vychlemtat, } \\
\text { vymlasknout }\end{array}$ & $3 / 6$ & $\begin{array}{l}\text { (wychlipać, } \\
\text { wychłeptać) }\end{array}$ & $2 / 6$ \\
\hline formacje fazowe & $\begin{array}{l}\text { zamlaskat, zasrkat, za- } \\
\text { šplouchat, zachroupat }\end{array}$ & $4 / 6$ & $\begin{array}{l}\text { (zachlupać, } \\
\text { zamlaskać) }\end{array}$ & $2 / 6$ \\
\hline formacje kierunkowe & $\begin{array}{l}\text { odsrkat, usrknout, } \\
\text { vsrkat, přechroupnout, } \\
\text { rozchroupat, uchroup- } \\
\text { nout, rozšplíchat, vhltat }\end{array}$ & $4 / 6$ & (odchlipać) & $1 / 6$ \\
\hline $\begin{array}{l}\text { *zmiana aspektu } \\
\text { (kategoria fleksyjna) }\end{array}$ & $\begin{array}{l}\text { pohltit, přehltnout, zhl- } \\
\text { tat sesrknout, usrkovat, } \\
\text { schlamstat, schroupat }\end{array}$ & $4 / 6$ & $\begin{array}{l}\text { (połknąć, prze- } \\
\text { łknąć) }\end{array}$ & $2 / 6$ \\
\hline $\begin{array}{l}\text { *przymiotniki (bez } \\
\text { analizy semantycz- } \\
\text { nej) }\end{array}$ & $\begin{array}{l}\text { chlemstavý, chroupavý, } \\
\text { hltavý, hltný, srkavý, } \\
\text { šplouchavý }\end{array}$ & $5 / 6$ & $\begin{array}{l}\text { chlupki, chrup- } \\
\text { ki, połykowy, } \\
\text { łykawy, chru- } \\
\text { pliwy }\end{array}$ & $4 / 6$ \\
\hline
\end{tabular}


Mimo różnic widocznych w strukturze TPS potencjał obu języków na I takcie derywacji można uznać za podobny. Nie da się ukryć, że analizie poddano tylko fragment klasy leksykalno-semantycznej, jaką stanowią czasowniki dźwiękonaśladowcze. Poszerzenie zbioru analizowanych gniazd prawdopodobnie wyrówna proporcje między liczbą znaczeń konstytuujących TPS obu języków, a puste klatki TPS języka polskiego mogą się zapełnić — sugerują to wystąpienia jednego czy dwóch derywatów o znaczeniu kierunkowym, kompletywnym czy fazowym.

Szczególnie interesujący jest rezultat konfrontacji łańcuchów słowotwórczych. Gradualny proces derywacji od podstaw bardziej produktywnych (bo tworzących głębsze gniazda) obu języków jest odmienny. Derywowane są inne części mowy: w języku czeskim są to przymiotniki i przysłówki, w języku polskim rzeczowniki i czasowniki. Nie można jednak przewidzieć, jak będzie wyglądał rezultat konfrontacji kolejnych trój- i czteroelementowych łańcuchów słowotwórczych. Przeprowadzona analiza wskazuje, że im głębiej wejdziemy w strukturę gniazd czasowników onomatopeicznych, tym bardziej odmienny okazuje się potencjał obu języków.

\section{Bibliografia}

\section{Źródła}

Pędzik P., Narodowy korpus języka polskiego. Wyszukiwarka PELCRA dla danych NKJP (NKJP), red. A. Przepiórkowski et al., PWN, Warszawa 2012, http:www.nkjp.uni.lodz.pl.

Slovník spisovného jazyka českého (SSJČ), red. B. Havránka, „Ústav pro jazyk český ČSAV”, Praha 1960-1971.

Słownik gniazd słowotwórczych współczesnego języka ogólnopolskiego (SGS), t. 3-4, red. M. Skarżyński, Towarzystwo Wydawnicze „Historia Iegellonica”, Kraków 2004.

SYN 2015: reprezentativni korpus psané češtiny (SYN 2015), red. M. Křen et al., Ústav Českého národního korpusu FF UK, Praha 2015, http://www.korpus.cz.

\section{Literatura}

Bańko M., Stownik onomatopei czyli wyrazów dźwięko- i rucho-naśladowczych, PWN, Warszawa 2009.

Bańko M., Wspótczesny polski onomatopeikon, PWN, Warszawa 2008.

Burkacka I., Porównawcza analiza gniazdowa wybranych leksemów neutralnych $i$ nacechowanych ekspresywnie, Dom Wydawniczy ELIPSA, Warszawa 2001.

Dokulil M., Teoria derywacji, przeł. A. Bluszcz, J. Stachowski, Zakład Narodowy im. Ossolińskich, Wrocław 1979.

Dokulil M., Tvořeni slov v češtině, t. 1. Teorie odvozování slov, Nakladatelství Československé Akademie Věd, Praha 1962.

Dokulil M., Krouz J., Mluvnice češtiny, t. 1. Fonetika. Fonologie. Morfonologie a morfemika. Tvoření slov, Nakladatelství Československé Akademie Věd, Praha 1986. 
Gramatyka wspótczesnego języka polskiego, t. 2, red. R. Grzegorczykowa, R. Laskowski, H. Wróbel, PWN, Warszawa 1999.

Jadacka H., Rzeczownik polski jako baza derywacyjna. Opis gniazdowy, PWN, Warszawa 1995.

Jochym-Kuszlikowa L., Jednostki systemowe stowotwórstwa a polsko-rosyjskie badania konfrontatywne, „Slavia Orientalis” 29, 1980, z. 1-2.

Jochym-Kuszlikowa L., Metoda analizy gniazdowej w konfrontatywnych badaniach stowotwórstwa współczesnego języka polskiego i rosyjskiego, Wydawnictwo Naukowe WSP, Kraków 1982.

Karpiłowska E.A., Gniazda słów jako językowy obraz świata. Perspektywy badań porównawczych, „LingVaria” 2, 2007, nr 2 (4).

Nagórko A., Zarys gramatyki polskiej, Wydawnictwo Naukowe PWN, Warszawa 2003.

Šmilauer V., Novočeské tvořeni slov, Státní pedagogické nakladatelství, Praha 1971.

Szymański T., Derywacja czasowników onomatopeicznych i ekspresywnych w języku bułgarskim, Zakład Narodowy im. Ossolińskich, Wrocław 1977.

Земская Е.А., О парадигматических отношениях в словообразовании, [w:] Русский язык. Вопросы его истории и современного состояния, red. Н.Ю. Шведовей, Наука, Москва 1978.

\section{Selected onomatopoeic verbs in Czech and Polish languages - word-forming potential}

\section{Summary}

The article is a contrastive analysis of word-forming potential for six Czech and Polish onomatopoeic verbs, such as: HLTAT / ŁYKNAĆ́; 2) CHLEMTAT / CHŁEPTAĆ; 3) CHROUPAT / CHRUPAĆ; 4) MLASKAT / MLASKAĆ; 5) SRKAT / CHLIPAĆ; 6) ŠPLOUCHAT / CHLUPAĆ. Using methodology of word-formation nests, two aspects of these words were analyzed: 1) abstract word-forming paradigm, 2) a word-forming chain. The analysis showed that in both languages onomatopoeic verbs quite regularly will derive verbs naming the result of the action and the verbs expressing intensity or weakening of the action. In Czech language there are also verbs naming completion of the action, verbs accentuating the beginning of the action or its direction. Word-forming chains are different: Czech are constituted by: verb $\rightarrow$ adjective $\rightarrow$ adverb, Polish by: verb $\rightarrow$ noun $\rightarrow$ verb.

Keywords: word-forming, verbs, Czech, language, Polish, word-forming nest, onomatopoeia

\section{Ke slovotvornému potenciálu zvukomalebných sloves $\mathrm{v}$ češtině a polštině}

\section{Obsah}

Záměrem autorky je konfrontovat slovotvorný potenciál onomatopoických sloves češtiny a polštiny spojených s jídlem a pitím, např.: 1) HLTAT/ŁYKNĄĆ; 2) CHEMLAT/CHŁEPTAĆ; 3) CHROUPAT/CHRUPAĆ; 4) MLASKAT/MLASKAĆ; 5) SRKAT/CHLIPAĆ; 6) ŠPLOUCHAT/ CHLUPAĆ. Používá při tom metodologii slovotvorných hnízd, což znamená 1) vertikální analýzu hnízda - až na typický slovotvorný svazek, 2) horizontální — postupnou derivaci, kterou lze po- 
psat v rámci slovotvorných řetězců. Z analýzy vyplývá, že se v obou jazycích derivují substantiva s významem výsledků děje a slovesa vyjadřující zesílení nebo zeslabení děje. K typickému českému slovotvorném svazku patří také slovesa s významem úplnosti děje, slovesa zdůrazňující začátek procesu nebo jeho směr. Slovotvorné řetězce jsou v obou jazycích odlišné: v češtině je tvoří základní sloveso $\rightarrow$ adjektivum $\rightarrow$ adverbium; v polštině: základní sloveso $\rightarrow$ substantivum $\rightarrow$ sloveso.

Klíčová slova: slovotvorný potenciál, sloveso, čeština, polština, jazyk, slovotvorba, hnízdo slovotvorné, onomatopoeia 